\title{
The Impact of Bioactive Lipids on Cardiovascular Development
}

\author{
Alexander Kleger, ${ }^{1,2}$ Stefan Liebau, ${ }^{3}$ Qiong Lin, ${ }^{4}$ Götz von Wichert, ${ }^{5}$ and Thomas Seufferlein ${ }^{6}$ \\ ${ }^{1}$ Department of Internal Medicine I, University of Ulm, 89081 Ulm, Germany \\ ${ }^{2}$ Institute of Molecular Medicine and Max-Planck-Research Group on Stem Cell Aging, University of Ulm, 89081 Ulm, Germany \\ ${ }^{3}$ Institute for Anatomy and Cell Biology, Ulm University, 89081 Ulm, Germany \\ ${ }^{4}$ Institute for Biomedical Engineering, Department of Cell Biology, RWTH Aachen University Medical School, 52074 Aachen, Germany \\ ${ }^{5}$ Department of Internal Medicine I, Martin Luther University Halle-Wittenberg (Saale), 06120 Halle, Germany \\ ${ }^{6}$ Department of Internal Medicine I, Division of Medicine, Martin Luther University Halle-Wittenberg (Saale), 06120 Halle, Germany
}

Correspondence should be addressed to Alexander Kleger, alexander.kleger@uni-ulm.de and Thomas Seufferlein, thomas.seufferlein@uk-halle.de

Received 15 April 2011; Accepted 5 June 2011

Academic Editor: Gabriela Kania

Copyright ( $\odot 2011$ Alexander Kleger et al. This is an open access article distributed under the Creative Commons Attribution License, which permits unrestricted use, distribution, and reproduction in any medium, provided the original work is properly cited.

Lysophospholipids comprise a group of bioactive molecules with multiple biological functions. The cardinal members of this signalling molecule group are sphingosylphosphorylcholine (SPC), lysophosphatidic acid (LPA), and sphingosine 1-phosphate (S1P) which are, at least in part, homologous to each other. Bioactive lipids usually act via G-protein coupled receptors (GPCRs), but can also function as direct intracellular messengers. Recently, it became evident that bioactive lipids play a role during cellular differentiation development. SPC induces mesodermal differentiation of mouse ES cells and differentiation of promyelocytic leukemia cells, by a mechanism being critically dependent on MEK-ERK signalling. LPA stimulates the clonal expansion of neurospheres from neural stem/progenitor cells and induces c-fos via activation of mitogen- and stress-activated protein kinase 1 (MSK1) in ES cells. S1P acts on hematopoietic progenitor cells as a chemotactic factor and has also been found to be critical for cardiac and skeletal muscle regeneration. Furthermore, S1P promotes cardiogenesis and similarly activates Erk signalling in mouse ES cells. Interestingly, S1P may also act to maintain human stem cell pluripotency. Both LPA and S1P positively regulate the proliferative capacity of murine ES cells. In this paper we will focus on the differential and developmental impact of lysophospholipids on cardiovascular development.

\section{Origin and Synthesis}

1.1. Sphingosylphosphorylcholine: Origin and Synthesis. Lysosphingomyelin or sphingosylphosphorylcholine (SPC) has been initially identified in the brain of Niemann Pick type A patients [1]. SPC acts as both an extracellular and intracellular signalling molecule. Although the origin of circulating SPC is not well characterized, activation of platelets during clotting is one likely mechanism since serum contains higher concentrations of SPC than plasma [2-4]. SPC is synthesized from either sphingomyelin or other so far unknown molecules by different metabolic pathways. In atopic dermatitis, sphingomyelin deacylase activity is enhanced generating SPC and resulting in sphingomyelin depletion. This, in turn, leads to decreased ceramide levels that may be the cause of barrier dysfunction in patients suffering from atopic dermatitis [5]. In addition, certain diseases, for example, Niemann-Pick type a that exhibit pathologic SPC accumulation in different organs are characterized by a lack of acid sphingomyelinase activity [1]. One possible explanation for this effect might be that high levels of sphingomyelin lead to an enhanced degradation by $\mathrm{N}$ deacylation [3].

1.2. Sphingosine-1-Phosphate: Origin and Synthesis. Sphingosine-1-phosphate (S1P) consists of the 18-carbon base sphingosine and a phosphate group at the $\mathrm{C} 1$ position. Sphingosine is phosphorylated to S1P by either sphingosine kinase 1 or 2. S1P can then be metabolized by the S1P lyase to phosphoethanolamine and hexadecenal, which are subsequently metabolized into glycerophosph lipids and 
phosphatidylethanolamine, respectively. Conversely, S1Pphosphohydrolase, an ectoenzyme localized in the plasma membranes of cells, regenerates sphingosine by dephosphorylating S1P [6-9]. On the other hand, sphingosine can be rephosphorylated to S1P [10]. One major source of circulating S1P is activated platelets which contain a highly active sphingosine kinase but no S1P lyase [11]. Besides platelets, red blood cells have been identified to contain high amounts of S1P [12-14]. Further S1P sources are provided by direct cellular uptake $[8,15]$. Clair and coworkers demonstrated thatautotaxinhydrolyzes SPC to S1P. This exoenzyme potently induces tumor cell motility and enhances experimental (in vitro) metastasis as well as angiogenesis [16]. However, the physiological relevance of the conversion of SPC to S1P by this mechanism is as yet unclear, since there is no detectable S1P in mice lacking sphingosine kinase 1 and 2 [17].

1.3. Lysophosphatidic Acid: Origin and Synthesis. Lysophosphatic acid (LPA) is a glycerophospholipid with a glycerol backbone. Variability in the satellite groups generates distinct subforms of LPA with different biological functions [18-21]. LPA can be de novo synthesized either by esterification of glycerol-3-phosphate via glycerol phosphate acyltransferase (GPAT) or by 4 other metabolic pathways: (i) reduction of acyl dihydroxy acetone phosphate, (ii) phosphorylation of monoacylglycerol (MAG) by the monoacylglycerol kinase, (iii) deacylation of phosphatidic acid (PA) by PLA1 or PLA2, or (iv) via autotaxin hydrolysis of SPC [22-24]. Degradation of LPA is mediated through either dephosphorylation to MAG by lipid phosphohydrolases of the PAP type 2 family (LPP1-3) or conversion to PA by LPA acyltransferase (LPAAT) or to glycerol-3-phosphate by lysophospholipase [9], respectively.

\section{Bioactive Lipid Receptors and Signalling}

Bioactive lipid receptors belong to the family of G-protein coupled receptors (GPCRs) and are termed LPAR1-5, S1PR1-5, OGR1, GPR4, and GPR12, respectively [25-27]. Recently, the LPA receptor family has been extended to the GPCRs P2Y5, GPR87, and P2Y10 which have been shown to bind both S1P and LPA [28-32]. Especially, OGR1 and GPR4 are believed to have a dual function in both lipid signalling and proton sensing [33]. All GPCRs are proteins containing seven transmembrane domains with an extracellular $\mathrm{N}$ terminus and an intracellular C-terminus [34, 35]. There are two arginines in the extracellular loops one and three of the S1P and LPA receptors, forming an ion pair with the phosphates of LPA and S1P. SPC receptors must have a basic and acidic residue in order to interact with the ammonium and the phosphate residues of SPC. An additional acidic residue may be required to interact with the choline base. till now, three high-affinity receptors have been identified: OGR1, GPR4, and GPR12. Most likely, a ligand-binding pocket is formed by basic and acidic amino acids in the second and third extracellular loop similar to the S1P and LPA receptors [36]. In addition, lipid GPCRs also form heterodimers with each other [37]. For further review of lipid receptor function please refer to [25]. Downstream signalling of these receptors is linked to all types of G-proteins $G_{s}, G_{i}$, $\mathrm{G}_{\mathrm{q}}$, and $\mathrm{G}_{12 / 13}$, respectively [38]. Distinct G-proteins activate a variety of signalling cascades, predominantly, the MEKERK signalling cascade [39-41] but also crosstalk with other pathways that are ascribed with respect to bioactive lipid signalling [42].

\section{Lysophospholipids and Their Impact on Cardiovascular Development}

Little is known about bioactive lipids and their functions in cardiogenesis despite the fact that several lipid receptors are expressed in the cardiac derivates. Most of the so far published data regarding this link focus on acute effects mediated by the lipids. Several studies have addressed the effect of bioactive lipids on cardiac function at the signal transduction level, for example, by modulating cAMP signalling [43] and ion conduction followed by changes in intracellular ion concentrations in the heart. However, the effects of ion conduction on the sarcoplasmatic reticulum and cell membrane differ between bioactive lipids such as S1P and SPC [44]. A study by Nofer et al. has shown that lysophospholipids stimulate endothelial nitric oxide production thereby regulating the vascular tone [45]. Nitric oxide also plays a crucial role in the mobilization and function of endothelial progenitor cells, an important bone marrow-derived cell type responsible for endothelial damage repair,neovascularization and generation of collaterals [4648]. Formation of new blood vessels is crucial for both embryonic development and homeostasis in the adult organism. Regarding the expression pattern of lipid receptors and further development of receptor knockout models, it has been revealed that bioactive lipids play an important role during blood vessel formation [49]. Therefore the following passage will focus on the effects of SPC, S1P, and LPA on mesodermal development and differentiation, predominantly cardiogenesis and angiogenesis.

\subsection{Sphingosylphosphorylcholine}

3.1.1. Lipid Receptors in Pluripotent Embryonic Stem Cells of Mice and Men. With respect to stem cells in particular pluripotent cells the expression of each particular receptor type varies in distinct cell lines. Our own data show expression of all S1P and SPC receptors including OGR1 and GPR4 in R1 ES cells. S1PR1-4 and GPR4 are expressed at high levels. There were no major differences in receptor expression between undifferentiated ES cells, different EB stages, or different stages of ES cell outgrowths apart from a slight decrease in the S1PR5 expression level at EB day 2. However, Rodgers and colleagues did not detect S1PR4 in CGR8 and D3 ES cells [40, 41]. To clarify this issue, we analysed several sets of published transcriptome sets for the expression of several bioactive lipid receptors in ES and iPS cells derived from mice and men. As shown in Figures 1 and 2 virtually all bioactive lipid receptors are expressed in both iPS and ES cells from both species. There is no relevant difference 


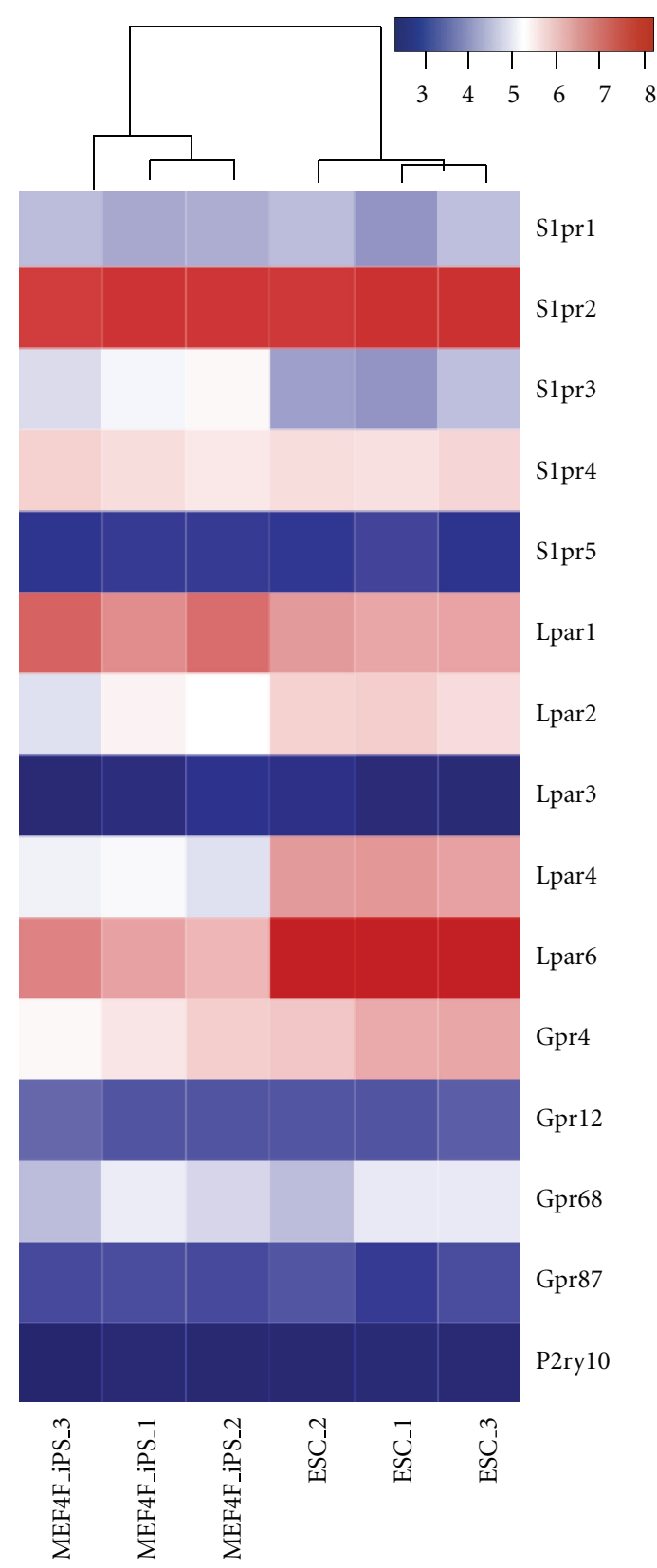

FIGURE 1: Lysophospholipid receptor expression in murine pluripotent stem cells. Heatmap of microarray gene expression of a list of mouse bioactive lipid receptors. Gene expression color key is shown in $\log 2$ scale. Microarray data were downloaded from the GEO database; accession numbers GSE10806.

between the ES and iPS cells pointing to the identity of both pluripotent cell types. However, the distinct expression levels of the particular subtypes differ in pluripotent cells of either murine or human origin. Summarized, bioactive lipid receptors are widely expressed throughout pluripotent cells of mice and men. Nevertheless, the precise function of each subtype remains unclear so far.

3.1.2. SPC Induces Cardiac Differentiation of Murine Embryonic Stem Cells. To date, there are very limited data linking

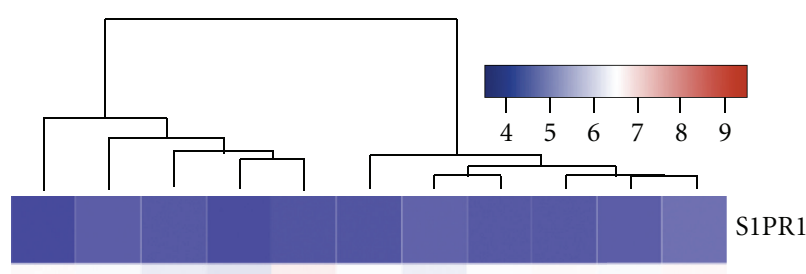

S1PR2
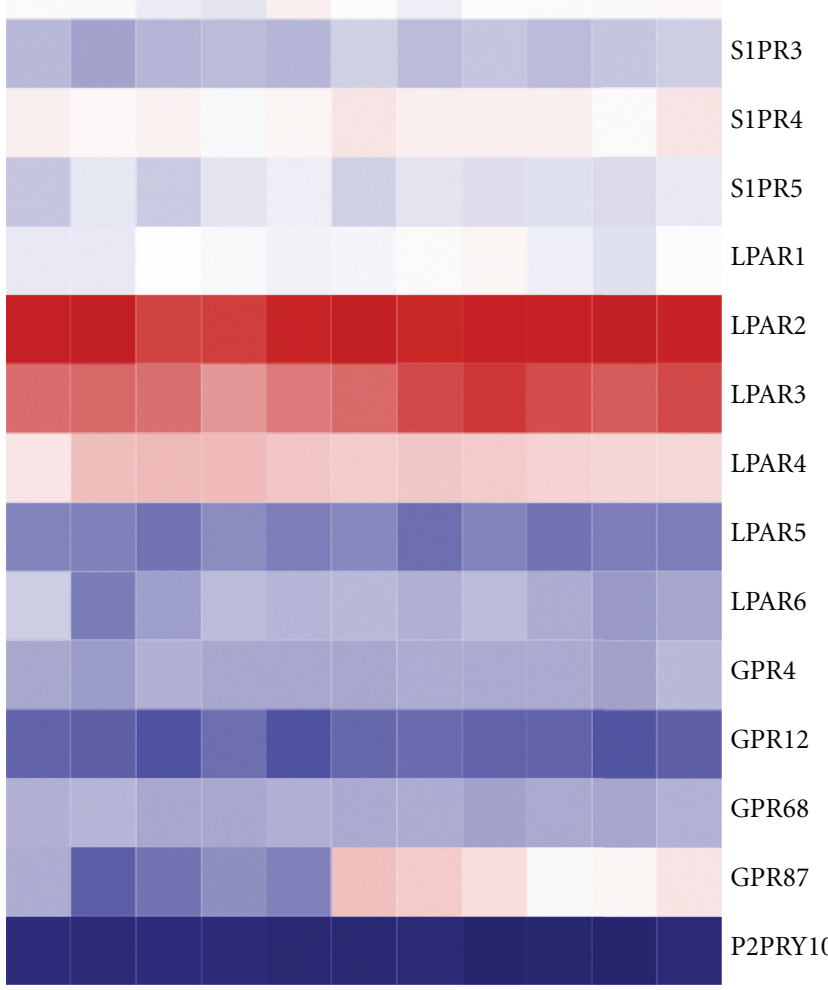

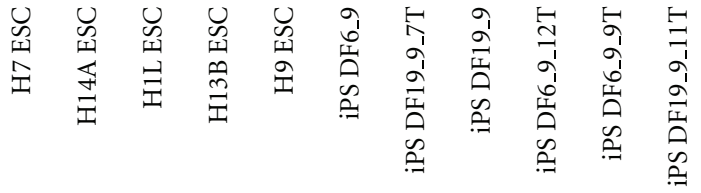

FIGURE 2: Lysophospholipid receptor expression in human pluripotent stem cells. Heatmap of microarray gene expression of a list of human bioactive lipid receptors. Gene expression color key is shown in $\log 2$ scale. Microarray data were downloaded from the GEO database; accession numbers GSE151716.

SPC to mesodermal or cardiac differentiation. Besides our own study using the embryonic stem cell differentiation model to characterize the role of SPC in cardiac development [40], there are few further studies showing that SPC differentiates pluripotent and multipotent stem cells [50, 51]. SPC similar to S1P stimulates cardiac ES cell differentiation at the level of both morphology and gene expression. However, there was no obvious difference regarding cardiac subtype formation since SPC increased cardiogenesis during all IVD stages [40]. Skeletal muscle cells and cardiac cells arise from the same germ layer [52]. Consequently whole germ layer induction by SPC is unlikely since otherwise both myogenic and cardiac cells would have been increased, suggesting a defined role in later stages of cardiac development, for 
example, on progenitor cells. A possible candidate is the recently identified multipotent cardiovascular progenitor which gives rise to cardiomyocytes, endothelial, and vascular smooth muscle cells [52]. These cells are defined by the expression of the vascular endothelial growth factor receptor 2 (VEGFR2/FLK1) which was recently shown to crosstalk with SPC signalling especially during tube formation [42]. This assumption is supported by the finding that SPC supports vessel formation in an EB sprouting assay and furthermore induces expression of endothelial markers (A. Kleger, unpublished observations). SPC also displays proliferation inducing properties by influencing ERK-signalling $[53,54]$. Also, in ES cells, SPC leads to ERK-phosphorylation, suggesting that the increased number of cardiac cells could be caused by progenitor cell proliferation (Figure 3 ). This is unlikely as the SPC-induced gene expression profiles were both atrial (alpha-myosin heavy chain) and ventricular (myosin light chain, MLC-2v). Realtime PCR analysis of both transcripts exhibited similar expression profiles supporting the progenitor cell hypothesis. Simply increased proliferation would not increase specialized cardiac cells marked by increased MLC-2v expression. However, there are data that both SPC and S1P share a common cardiac phenotype.

Similarly, as discussed in detail below, S1P treatment of EBs increases cardiac differentiation [55]. In addition, a developmental study using the zebra fish model revealed a $\mathrm{S} 1 \mathrm{P}$ receptor as a relevant candidate during cardiogenesis (see also S1P and cardiac development). This implicates a kind of "family affair" with respect to cardiac differentiation.

3.1.3. SPC Plays an Important Role in Angiogenesis. Further evidence linking SPC to mesodermal development and differentiation is given by the effect of SPC on angiogenesis. SPC induces differentiation of endothelial cells into capillary-like structures in vitro in addition to migration and chemotaxis of vascular smooth muscle cells $[56,57]$. Supporting evidence for a crucial role of SPC in angiogenesis arises from studies investigating its receptor GPR4. SPC induces GPR4-dependent vessel formation in vitro from HUVEC cells [42]. GPR4 deficiency leads to leaky blood vessels (e.g. spontaneous hemorrhages, dilated, tortuous subcutaneous blood vessels, and defective vascular smooth muscle cell coverage) during development and the receptor functions in blood vessels as a $\mathrm{pH}$ sensor [49]. S1P and SPC activate distinct MAP kinase isoforms and increase $\left[\mathrm{Ca}^{2+}\right]_{i}$ via different mechanisms in rat cerebral arteries. This does not affect the ability of both compounds to activate CREB, although this occurs via different pathways [58]. For further information please refer to [59] where the involved signalling cascades are discussed in more detail. Piao and colleagues used a rat aortic ring assay. SPC significantly stimulated the sprouting of endothelial cells from the aortic ring and markedly enhanced the chemotactic migration and capillary-like tube formation. This effect was dependent on a urokinase-type plasminogen activator (uPA), an important regulator of angiogenesis [60].

3.1.4. SPC Modulates Differentiation of Several Stem Cell Populations. Besides end-differentiation of already commit- ted endothelial and vascular smooth muscle cells, SPC also modulates proliferation and differentiation of multipotent adult stem cells. Jeon and colleagues investigated SPC effects in a series of manuscripts on human adipose-tissue-derived mesenchymal stem cells (hATSCs). In the first study Jeon et al. showed induction of apoptosis under involvement of the mitochondrial death pathway by SPC in a concentrationdependent manner ( $>10 \mu \mathrm{M}$ SPC). This effect was critically dependent on ERK activity [61]. In lower concentrations the compound induced proliferation of the same cell type in a JNK-dependent manner without any involvement of the ERK pathway [51]. A further study revealed SPC as a differentiation-inducing agent for hATSCs to smooth muscle cells. The authors discovered a new signalling pathway for SPC through Gi/o-ERK-dependent autocrine secretion of TGF-beta, which activates a Smad2-SRF/myocardindependent pathway (Figure 3). Despite the fact that hATSCs do not express any known SPC receptors, in all studies SPC effects seemed to be receptor dependent. This suggests either a crosstalk with further signalling cascades (e.g., TGF-beta or VEGF signalling) or involvement of so far unknown SPC receptors. Another possible explanation would be an SPCstimulated release of other bioactive lipids like S1P or LPA via, for example, autotoxin [50]. The most recent study of the group identified fibronectin (FN) as an agent produced by hATSC after SPC treatment via the pathway described above. Since fibronectin is essential for cell recruitment and adhesion during wound healing and angiogenesis, the authors concluded that SPC-induced FN expression plays a pivotal role in wound healing by stimulating adhesion and recruitment of leukocytes [62]. Furthermore, SPCmediated TGF-beta release seems not to be restricted to hATSCs, as also endothelial cells react with release of the anti-inflammatory cytokine after HDL treatment including SPC and S1P as active compounds [63]. Therefore different local SPC concentrations in distinct microenvironments and niches seem to regulate the effect of the bioactive lipid.

In summary there are many studies suggesting that SPC plays a pivotal role in mesodermal development with respect to cardiogenesis and angiogenesis. Furthermore the key role of SPC in angiogenesis is defined by coordinated migration of both endothelial cells and vascular smooth muscle cells in response to the changing gradients of this bioactive lipid messenger. SPC effects on both cardiac and vascular development could be caused by modulation of a common progenitor as described in [52].

\subsection{Sphingosine-1-Phosphate}

3.2.1. Cardiovascular Receptor Expression. Expression studies of the S1P receptor family suggest the particular importance of S1P in the cardiovascular system. Lung and heart show the highest overall expression of S1PR1, S1PR2, and S1PR3 $[64,65]$. S1PR2 and S1PR3 receptors expression is generally lower than that of S1PR1 receptors in the heart, although distribution within cardiac subregions (e.g., ventricle, septum and atrium) is similar $[66,67]$. Beyond that, S1P receptors are expressed with a distinct expression pattern in the different aortic cell types. High expression levels of S1P 


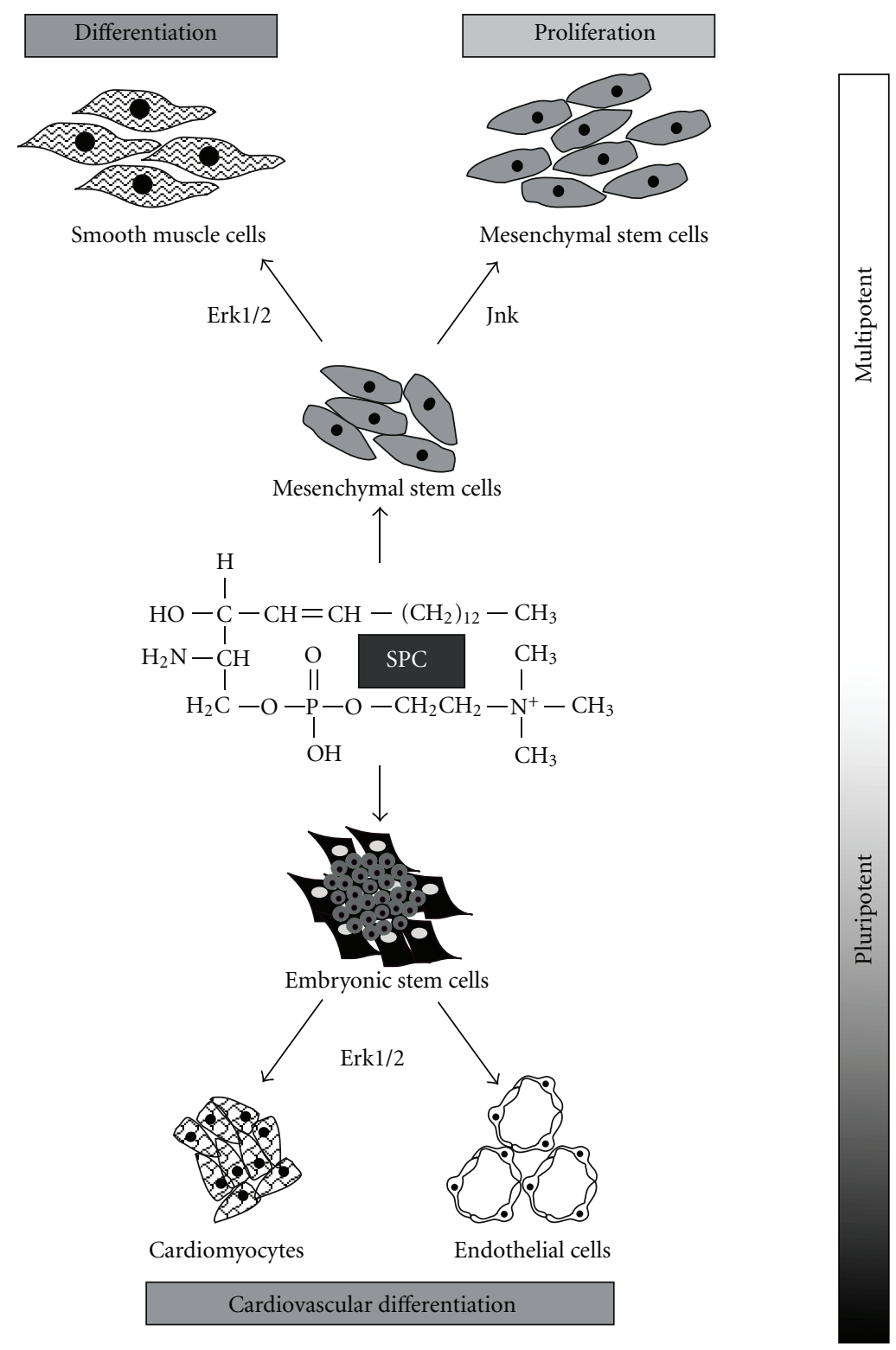

FIGURE 3: Schematic illustration of SPC-induced differentiation in murine multipotent and pluripotent stem cells. Signaling pathways mediating the respected phenotype are noted next to black arrows.

receptors seem to be a general characteristic of endothelial cells [67-69]. Most of the work was done to clarify acute effects of S1P and other bioactive lipids on the cardiovascular system, for example, the role of S1P during protection of heart ischemia has been evaluated in several studies [70-72]. Besides developmental functions and ion channel modulation, S1P induces cardiomyocyte hypertrophy mainly via the S1PR1 receptor and subsequently via a $G$ protein through the ERK pathway and via the Rho pathway [73].

3.2.2. S1P and Cardiac Development In Vivo. A developing action field of bioactive lipids is their role in promoting cardiomyocyte survival and their contribution to ischemic preconditioning. There are several lines of evidence suggesting that in vivo levels of bioactive lipids influence cardiomyocyte survival and regeneration. For example, the stressactivated enzyme S1P lyase (SPL) which metabolizes S1P has been identified as therapeutic target for ischemia/reperfusion injury of the heart $[74,75]$. Inhibition of SPL results in elevated levels of S1P [74]. In aging hearts S1P exhibits cardioprotective effects during cardiac injury in a pre- and postconditioning experimental setup [75]. Indeed, local S1P levels seem to regulate not only acute but also developmental aspects of S1P. The first clue for a link between S1P and cardiac development/differentiation was given by a study from Kupperman et al. in the zebrafish model. The authors 
investigated the zebrafish analogon of S1PR2, miles apart (mil), and found that mil specifically affects the migration of heart precursors to the midline resulting in cardia bifida. Cross-transplantation studies suggest that S1P provides clues for the fusion of the bilateral heart progenitors by generating an environment permissive for migration [76]. This was further investigated by Kawahara et al. who found that a mutant of the sphingolipid transporter 2 (spns2) leads to a similar cardiac defect as the mil mutant. They also could show that spns 2 is involved in the secretion of S1P and thereby regulating myocardial precursor migration (Figure 4, [77]). Further evidence is given by means of a primary culture system of embryonic zebrafish cells. The interaction of cardiac precursors with fibronectin, that is, a major component of the extracellular matrix, seems to be critical for precursor migration [78]. Recently, a report using a mouse ex vivo culture system underlined inalienability of S1P for cardiac development in a mammalian system. Wendler and Rivkees showed that both increased and decreased S1P levels alter cardiac development by reduced mesenchyme formation. While decreased S1P levels induce cell death, increased S1P levels inhibit cellular migration, both resulting in a reduced amount of mesenchymal transformed cells. S1PR2 was found to be the most likely candidate for mediating these effects [79]. Interestingly, Osborne et al. detected another player involved in the signalling and trafficking of S1P, namely, two of hearts (toh), a spinster homologue. They found that the mutations are causative of a cardiac phenotype comparable to that of S1P dysfunction [80]. In general, developmental acquisition of tolerance to environmental stress may be contingent upon acquisition of protective biochemical mechanisms (e.g., S1P-mediated cellular survival) or simply due to increased cell numbers (e.g., S1P-induced cellular proliferation) [81]. Both issues are eventually targeted by S1P during development [44, 82-84]. Regarding intracellular signalling VEGF could be a possible target of S1P. VEGF activates the sphingosine kinase and increases S1P levels in human umbilical vein endothelial cells [85]. Chang and colleagues showed that a distinct regulation pattern of VEGF is essential for regular valve formation and morphogenesis [86]. These data indicate that S1P could be a possible candidate for indirect mediation of VEGF signalling by induction of sphingosine kinase. Therefore, lipid signalling and especially accurate regulation of local concentration in this particular niche are indispensable for proper function during mammalian heart development and cellular differentiation into cardiac tissue.

3.2.3. S1P Signalling during Vasculogenesis-Importance of VEGF Crosstalk. VEGF is probably the most important regulator of angiogenesis in both physiological and pathological vessel formation. There are several studies supporting a crosstalk of VEGF and bioactive lipid signalling. However, this process seems to be rather complicated: several mechanisms, for example, transactivation, upregulation, or downstream activation, are propagated [44]. Igarashi and colleagues observed that VEGF induces S1PR1 expression. This process consequently leads, to enhanced intracellular signalling responses to S1P and the potentiation of S1P- mediated vasorelaxation. S1P and VEGF signalling leads to, for example, eNOS regulation which in turn sensitizes the vascular endothelium to the effects of lipid mediators by promoting the induction of S1P1 receptors [87]. Furthermore, sphingosine kinase induction has been reported by VEGF with subsequently altered Ras signalling [85]. Endo et al. found that S1P induces membrane ruffling of human umbilical vein endothelial cells via the vascular endothelial growth factor receptor 2 (VEGFR-2) [88]. Most recently, another study proposed that VEGF induces S1PR3 induction which is necessary for downstream AKT3 signalling [89]. In summary, there is a well-documented, but still unclear crosstalk between two angiogenic signalling pathways, which is not surprising, given the fact that hypoxia, a consequence of insufficient vessel formation, induces VEGF. This issue can be clearly followed in a study of Chae et al. They showed that S1PR1 knockout mice suffer from defect limb formation due to insufficient vessels formation caused by impaired S1P signalling via S1PR1 leading to hypoxia and VEGF induction with secondary insufficient hypervascularisation [90].

\subsubsection{S1P Receptors Decide on the Angiogenic Phenotype} In Vivo. S1P seems to function on all levels of vascular development. Lee and colleagues showed S1P induced tube formation in umbilical vein endothelial cells by means of a matrigel assay [91]. In several further studies this effect has been proven in different model systems and with distinct endothelial cell types. Tube formation was critically dependent on ERK signalling [44, 92, 93]. Recently, HDL proteins have been implicated in serving as a platform for the delivery of S1P. Using reconstituted high-density lipoprotein (rHDL), Matsuo and colleagues investigated the same effects as induced by direct incubation with S1P [94].

The last step of angiogenesis is the recruitment of mural cells, for example, pericytes in capillaries and vascular smooth muscle cells of arteries [95]. Distinct functions for S1P in both smooth muscle cells and mural cells have been reported: S1P modulates and increases smooth muscle cell migration and differentiation by Rho Kinase [96] and by RhoA-mediated activation of serum response factor and involvement of the SRF cofactor, myocardin-related transcription factor A (MRTF-A). S1P also moderately stimulated SMC proliferation, a process that was dependent upon ERK and involved activation of another SRF cofactor, Elk1 [97]. S1PR1 null mice exhibited embryonic haemorrhage leading to intrauterine death around embryonic day 13 and incomplete limb development. Interestingly, these animals displayed normal vasculogenesis and angiogenesis but failed to recruit both vascular smooth muscle cells to arteries and pericytes to capillaries [98]. In the limbs, lack of S1PR1 results in aberrant chondrocyte condensation and irregular digit morphogenesis. The authors concluded that defective vascular development induced by lack of S1PR1 caused hypoxia. Secondary to hypoxia, HIF1 alpha and VEGF are induced and lead to hypervascularisation, ultimately disturbing limb morphogenesis [90]. In a later study, Allende and colleagues using a conditional S1PR1 knockout mouse model targeting endothelial cells found that S1PR1 null endothelium is defective in mural cell recruitment [99]. 
Physiological fusion of cardiac precursor pools

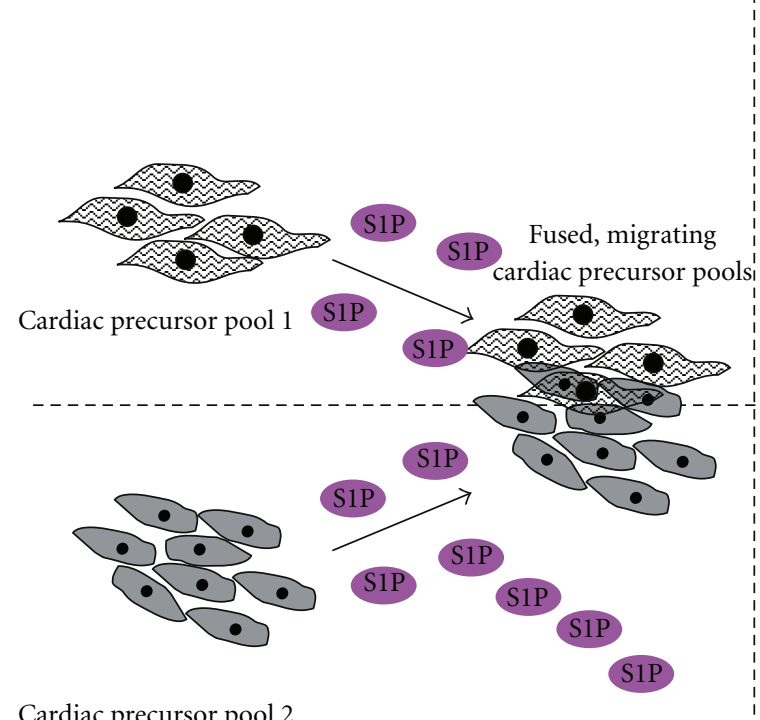

Cardiac bifida due to impaired precursor migration

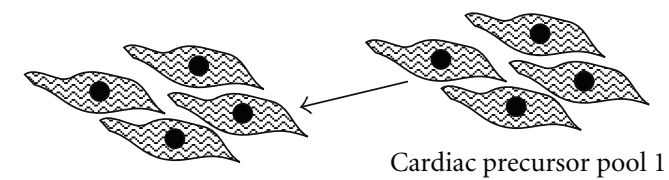

Cardiac precursor pool 1

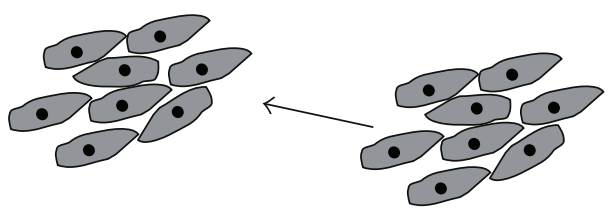

Cardiac precursor pool 2

Defective sphingolipid transporter 2

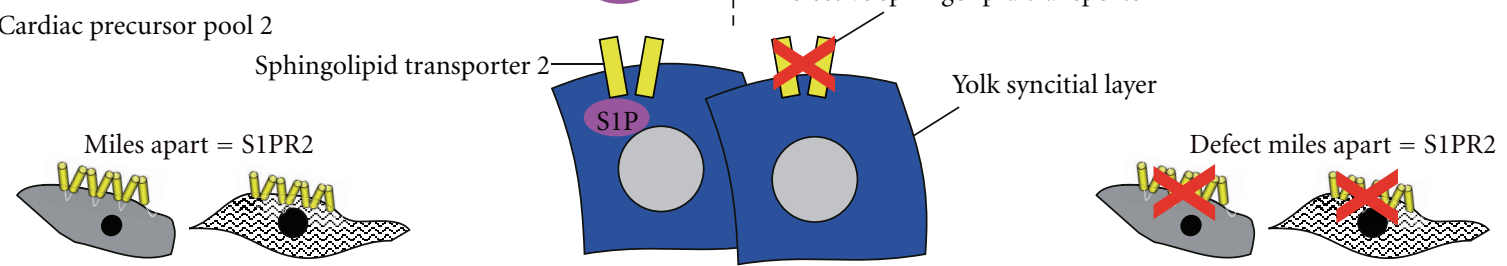

FIGURE 4: In vivo model of S1P function and its respective cofactors in the developing zebrafish.

S1P signalling on endothelial cells and bone marrow-derived stromal cells in vitro results in differentiation, proliferation, migration, and tube formation. Different studies revealed that especially S1PR1 but also S1PR2 and -3 to be crucial for these effects $[94,100]$. Since S1PR1 null animals displayed normal vasculogenesis and angiogenesis, it is likely that there is functional redundancy among members of the S1P receptor. This hypothesis is underlined by the fact that S1PR2 and -3 null mice reveal no apparent anatomical or physiological defects $[64,101]$. Kono and colleagues faced this issue and created subsequently different combinations of S1PR1-3 double null mice and triple null mice. They found that S1PR1 S1PR2 double null and S1PR1 S1PR2 S1PR3 triple null embryos displayed a substantially more severe vascular phenotype than embryos lacking only S1PR1. All these embryos completed vasculogenesis regularly but displayed immature vessels in the brain indicating that the S1PR1 and S1PR2 receptors are required for some aspects of vessel development during angiogenesis. In addition, the researchers found partial embryonic lethality and vascular abnormalities in S1PR2 S1PR3 double null embryos. Ultrastructural analysis of microvessels in the S1PR2 S1PR3 double null mice showed abnormal endothelial cells with thin cell bodies, suggesting that these vessels may be fragile and prone to rupture [102]. However, despite no obvious anatomical defects in either S1PR2 or S1PR3 null mice, S1PR2 null mice exhibit early life deafness which is associated with pathologic changes within the cochlea. Most likely this phenotype is caused by vascular disturbance within the stria vascularis. Additionally, it was reported, that S1PR2 knockout mice display a vascular dysfunction affecting the renal, mesenterical, and, furthermore, aortic hemodynamics [103]. S1PR2 S1PR3 double null mice display stronger defects even leading to head tilt while S1PR3 null mice do not share this phenotype [104]. These data further support the hypothesis of overlapping S1P receptor function with both partial redundancy and unique receptor properties. Apart from that there is growing evidence that S1PR2 also participates in pathological neovascularisation. Skoura et al. [105] found that S1PR2 null mice display reduced neovascularisation in response to ischemia-driven retinopathy. Furthermore, the inflammatory reaction that is usually concomitant to ischemic retinopathy was suppressed in mice lacking S1PR2. Therefore S1PR2 antagonism could be a potential target for treatment of pathologic neovascularisation [105].

3.2.5. S1P and the Recruitment of Stem/Progenitor Cells. Homing is the first process in which circulating hematopoietic cells actively cross the blood-bone-marrow-endothelium barrier and stay at least temporarily in the bone marrow compartment to undergo self-renewal. There is overwhelming evidence that circulating progenitor cells are responsible for vascular healing and remodelling under physiological and pathological conditions [106]. Usually stem/progenitor cells persist in a quiescent state in their niche. In case of angiogenesis or neovascularisation specific signals initiate differentiation, further mobilization, and homing of vascular progenitor cells [107]. Seitz et al. could already show 
that $\mathrm{S} 1 \mathrm{P}$ is acting on hematopoietic progenitor cells as chemoattractant via S1PR1. Given the fact that activated platelets represent a major source of extracellular S1P, stem cell homing may occur at sites of tissue injury in addition to the bone marrow [108]. Walter et al. found that incubation of patient-derived endothelial progenitor cells (EPCs) with S1P or its synthetic analogue FTY720 improved blood flow recovery in ischemic hind limbs. This phenomenon was critically dependent on S1PR3 activity since it was abolished in S1P3 null mice [109]. In a recent study from Donati and colleagues, S1P was found to be essential for mesoangioblast proliferation and survival [110]. In summarize, S1P is likely to act on different immature cell types regarding the mesendodermal germ layer.

3.3. Lysophosphatidic Acid. Similar to the other bioactive lipids LPA seems to be involved in modulation of cardiomyocyte signalling. Recently, elevated serum LPA concentrations in patients with myocardial infarction have been reported, indicating a role of LPA in cardiac pathophysiology [111]. In cultured neonatal cardiomyocytes, LPA induces via $\mathrm{LPA}_{1} / \mathrm{LPA}_{3}$ hypertrophy under involvement of AKT and $\mathrm{NF} \kappa \mathrm{B}$ signalling $[112,113]$. Furthermore, it prevents hypoxia-induced apoptosis in cardiomyocytes similar to S1P and SPC [82]. Hence, LPA is likely to play a role in left ventricular remodelling. Nevertheless, differentiation inducing effects of LPA in terms of cardiac development remain to be established. So far, a developmental role of LPA is restricted to the nervous system where LPA plays an elementary function during neurogenesis.

\subsubsection{LPA Functions Similarly But Not Equally as S1P during} Vasculogenesis. Regarding vessel formation LPA seems to induce similar but not equal effects compared to S1P. For example, LPA has been shown to induce expression of MMPs and migration of endothelial cells, both steps known to be critical for vessel formation $[114,115]$. However, LPA affects MMP induction and migration to a much lower extent than S1P though it most likely uses the same signalling pathways. Given the fact that LPA is a low-affinity ligand of, for example, the S1P receptor [116], it could be possible that LPA effects on endothelial cells are driven by S1P receptors $[100$, $114,115,117]$. In mesenchymal stem cells LPA fails to induce tube formation but promotes vascular network formation in murine E8.5 allantois explants, still, in both studies less efficaciously than S1P $[100,118]$. Despite controversial in vitro data, in vivo studies of receptor or enzyme knockouts affecting LPA signalling showed gross abnormalities including in angiogenesis. Homozygous LPAR1 null mice showed $50 \%$ neonatal lethality and reduced size caused by impaired suckling behaviour. Beside the neuronal phenotype LPAR1 null mice also suffered from craniofacial dysmorphism, uniformly notable by short snouts and widely spaced eyes. This phenotype is most likely due to loss of LPAR1 during development of facial bone tissue, where expression is usually strong [119]. In addition, a small group of the knock out animals displayed frontal hematoma. This could be explained by improper vasculogenesis, similar to the phenotype of S1Preceptor knock out studies showing abnormal limb/bone development [90]. However, given the small number of LPAR1 null pups developing frontal hematoma, functional angiogenic redundancy is likely also true for LPA receptors. This issue is underlined by data achieved from LPAR1 and LPAR2 double null animals showing a more severe phenotype. Therefore LPAR1 and LPAR2 are not essential for proper development but most likely involved in mediation of LPA-induced angiogenic signals [120]. In contrast, a recent study identified LPAR4 as a critical regulator of the structure and function of blood and lymphatic vessels [121]. The overall not severe phenotype of all single LPA receptor null animals stands in striking contrast with autotaxin null animals [122]. Lack of autotaxin leads to embryonic lethality around E9.5 with profound vascular defects in yolk sac and the embryos resemble the phenotype of animals lacking both small $G$-protein $G_{12}$ and $G_{13}$. These two $G$-proteins are major mediators of LPA receptor signalling [123]. Furthermore, ATX-deficient embryos showed allantois malformation, neural tube defects, and asymmetric headfolds [122]. However, developmental dysfunction is not only due to lack of LPA but also to excess shown by knock out studies of lipid phosphate phosphatases (LPPs), a group of enzymes involved in lipid phosphate biosynthesis. Escalante-Alcalde and colleagues disrupted the LPP3 gene leading to increased LPA levels. LPPR3 null mice failed to form a chorioallantoic placenta and yolk sac vasculature. Furthermore, some embryos exhibited shortening of the anterior-posterior axis and frequent duplication of axial structures [124]. To summarize this section, LPA and its distinct receptors are most likely, similar to the S1P-S1P receptor axis, functionally redundant and therefore only triple or quadruple knock outs would resemble the phenotype of ATX null animals and mirror, as major LPA synthesizer, an LPA-deficient phenotype. Hence, it seems crystal clear that developmental importance of LPA is not restricted to the neuronal systems but rather widely affects mammalian development.

\section{Conclusion}

There are several lines of evidence pointing to lysophospholipids or bioactive lipids as important regulators of stem cell differentiation in vitro and cardiovascular development in vivo. This has been established by a variety of studies using either knock out mouse models or embryonic stem cells as tools to recapitulate cardiovascular development. In particular S1P seems to be crucial for this particular system while LPA seems to be more pronounced in the nervous system. However, the SPC role in this process seems to be underdeveloped so far and needs further studies to dissect its developmental impact more precisely.

\section{Abbreviations}

SPC: Sphingosylphosphorylcholine

LPA: Lysophosphatidic acid

S1P: $\quad$ Sphingosine 1-phosphate

S1PR: Sphingosine 1-phosphate receptor

GPCRs: G-protein coupled receptors

MAG: Monoacylglycerol 
LPAR: Lysophosphatidic acid receptor

LPPs: $\quad$ Lipid phosphate phosphatases

ATX: Autotaxin

hATSC: Human adipose-tissue-derived mesenchymal stem cell

HUVEC: Human umbilical vein endothelial cell.

\section{Authors' Contribution}

A. Kleger and S. Liebau contributed equally to this paper.

\section{References}

[1] C. Rodriguez-Lafrasse and M. T. Vanier, "Sphingosylphosphorylcholine in Niemann-Pick disease brain: accumulation in type A but not in type B," Neurochemical Research, vol. 24, no. 2, pp. 199-205, 1999.

[2] K. Liliom, G. Sun, M. Bünemann et al., "Sphingosylphosphocholine is a naturally occurring lipid mediator in blood plasma: a possible role in regulating cardiac function via sphingolipid receptors," Biochemical Journal, vol. 355, no. 1, pp. 189-197, 2001.

[3] D. Meyer zu Heringdorf, H. M. Himmel, and K. H. Jakobs, "Sphingosylphosphorylcholine-biological functions and mechanisms of action," Biochimica et Biophysica Acta, vol. 1582, no. 1-3, pp. 178-189, 2002.

[4] N. Murata, K. Sato, J. Kon, H. Tomura, and F. Okajima, "Quantitative measurement of sphingosine 1-phosphate by radioreceptor- binding assay," Analytical Biochemistry, vol. 282, no. 1, pp. 115-120, 2000.

[5] J. Hara, K. Higuchi, R. Okamoto, M. Kawashima, and G. Imokawa, "High-expression of sphingomyelin deacylase is an important determinant of ceramide deficiency leading to barrier disruption in atopic dermatitis," Journal of Investigative Dermatology, vol. 115, no. 3, pp. 406-413, 2000.

[6] B. M. Buehrer and R. M. Bell, "Sphingosine kinase: properties and cellular functions," Advances in Lipid Research, vol. 26, pp. 59-67, 1993.

[7] H. Le Stunff, S. Milstien, and S. Spiegel, "Generation and metabolism of bioactive sphingosine-1-phosphate," Journal of Cellular Biochemistry, vol. 92, no. 5, pp. 882-899, 2004.

[8] A. Olivera and S. Spiegel, "Sphingosine kinase: a mediator of vital cellular functions," Prostaglandins and Other Lipid Mediators, vol. 64, no. 1-4, pp. 123-134, 2001.

[9] J. D. Saba and T. Hla, "Point-counterpoint of sphingosine 1phosphate metabolism," Circulation Research, vol. 94, no. 6, pp. 724-734, 2004.

[10] D. N. Brindley, "Lipid phosphate phosphatases and related proteins: signaling functions in development, cell division, and cancer," Journal of Cellular Biochemistry, vol. 92, no. 5, pp. 900-912, 2004.

[11] Y. Yatomi, F. Ruan, S. I. Hakomori, and Y. Igarashi, "Sphingosine-1-phosphate: a platelet-activating sphingolipid released from agonist-stimulated human platelets," Blood, vol. 86, no. 1, pp. 193-202, 1995.

[12] C. Bode, S. C. Sensken, U. Peest et al., "Erythrocytes serve as a reservoir for cellular and extracellular sphingosine 1phosphate," Journal of Cellular Biochemistry, vol. 109, no. 6, pp. 1232-1243, 2010.

[13] R. Pappu, S. R. Schwab, I. Cornelissen et al., "Promotion of lymphocyte egress into blood and lymph by distinct sources of sphingosine-1-phosphate," Science, vol. 316, no. 5822, pp. 295-298, 2007.

[14] P. Hanel, P. Andreani, and M. H. Graler, "Erythrocytes store and release sphingosine 1-phosphate in blood," The FASEB Journal, vol. 21, pp. 1202-1209, 2007.

[15] L. C. Boujaoude, C. Bradshaw-Wilder, C. Mao et al., "Cystic fibrosis transmembrane regulator regulates uptake of sphingoid base phosphates and lysophosphatidic acid: modulation of cellular activity of sphingosine 1-phosphate," Journal of Biological Chemistry, vol. 276, no. 38, pp. 3525835264, 2001.

[16] T. Clair, J. Aoki, E. Koh et al., "Autotaxin hydrolyzes sphingosylphosphorylcholine to produce the regulator of migration, sphingosine-1-phosphate," Cancer Research, vol. 63, no. 17, pp. 5446-5453, 2003.

[17] K. Mizugishi, T. Yamashita, A. Olivera, G. F. Miller, S. Spiegel, and R. L. Proia, "Essential role for sphingosine kinases in neural and vascular development," Molecular and Cellular Biology, vol. 25, no. 24, pp. 11113-11121, 2005.

[18] K. Bandoh, J. Aoki, A. Taira, M. Tsujimoto, H. Arai, and K. Inoue, "Lysophosphatidic acid (LPA) receptors of the EDG family are differentially activated by LPA species. Structureactivity relationship of cloned LPA receptors," FEBS Letters, vol. 478, no. 1-2, pp. 159-165, 2000.

[19] A. Tokumura, Y. Kanaya, M. Kitahara, M. Miyake, Y. Yoshioka, and K. Fukuzawa, "Increased formation of lysophosphatidic acids by lysophospholipase D in serum of hypercholesterolemic rabbits," Journal of Lipid Research, vol. 43, no. 2, pp. 307-315, 2002.

[20] A. Tokumura, K. Tominaga, K. Yasuda, H. Kanzaki, K. Kogure, and K. Fukuzawa, "Lack of significant differences in the corrected activity of lysophospholipase D, producer of phospholipid mediator lysophosphatidic acid, in incubated serum from women with and without ovarian tumors," Cancer, vol. 94, no. 1, pp. 141-151, 2002.

[21] E. J. Van Corven, A. Van Rijswijk, K. Jalink, R. L. Van Der Bend, W. J. Van Blitterswijk, and W. H. Moolenaar, "Mitogenic action of lysophosphatidic acid and phosphatidic acid on fibroblasts. Dependence on acyl-chain length and inhibition by suramin," Biochemical Journal, vol. 281, part 1, pp. 163-169, 1992.

[22] C. Pagès, M. F. Simon, P. Valet, and J. S. Saulnier-Blache, "Lysophosphatidic acid synthesis and release," Prostaglandins and Other Lipid Mediators, vol. 64, no. 1-4, pp. 1-10, 2001.

[23] C. Pagès, M. F. Simon, P. Valet, and J. S. Saulnier-Blache, "Lysophosphatidic acid synthesis and release," Prostaglandins and Other Lipid Mediators, vol. 64, no. 1-4, pp. 1-10, 2001.

[24] M. Umezu-Goto, Y. Kishi, A. Taira et al., "Autotaxin has lysophospholipase D activity leading to tumor cell growth and motility by lysophosphatidic acid production," Journal of Cell Biology, vol. 158, no. 2, pp. 227-233, 2002.

[25] D. Meyer zu Heringdorf and K. H. Jakobs, "Lysophospholipid receptors: signalling, pharmacology and regulation by lysophospholipid metabolism," Biochimica et Biophysica Acta, vol. 1768, no. 4, pp. 923-940, 2007.

[26] W. H. Moolenaar, L. A. Van Meeteren, and B. N. G. Giepmans, "The ins and outs of lysophosphatidic acid signaling," BioEssays, vol. 26, no. 8, pp. 870-881, 2004.

[27] S. Spiegel and S. Milstien, "Sphingosine-1-phosphate: an enigmatic signalling lipid," Nature Reviews Molecular Cell Biology, vol. 4, no. 5, pp. 397-407, 2003.

[28] Y. Shimomura, M. Wajid, Y. Ishii et al., "Disruption of $\mathrm{P} 2 \mathrm{RY} 5$, an orphan $\mathrm{G}$ protein-coupled receptor, underlies 
autosomal recessive woolly hair," Nature Genetics, vol. 40, no. 3, pp. 335-339, 2008.

[29] S. M. Pasternack, I. Von Kügelgen, K. A. Aboud et al., "G protein-coupled receptor P2Y5 and its ligand LPA are involved in maintenance of human hair growth," Nature Genetics, vol. 40, no. 3, pp. 329-334, 2008.

[30] K. Yanagida, K. Masago, H. Nakanishi et al., "Identification and characterization of a novel lysophosphatidic acid receptor, p2y5/LPA6," Journal of Biological Chemistry, vol. 284, no. 26, pp. 17731-17741, 2009.

[31] K. I. Tabata, K. Baba, A. Shiraishi, M. Ito, and N. Fujita, "The orphan GPCR GPR87 was deorphanized and shown to be a lysophosphatidic acid receptor," Biochemical and Biophysical Research Communications, vol. 363, no. 3, pp. 861-866, 2007.

[32] M. Murakami, A. Shiraishi, K. Tabata, and N. Fujita, "Identification of the orphan GPCR, P2Y10 receptor as the sphingosine-1-phosphate and lysophosphatidic acid receptor," Biochemical and Biophysical Research Communications, vol. 371, no. 4, pp. 707-712, 2008.

[33] H. Tomura, C. Mogi, K. Sato, and F. Okajima, "Protonsensing and lysolipid-sensitive G-protein-coupled receptors: a novel type of multi-functional receptors," Cellular Signalling, vol. 17, no. 12, pp. 1466-1476, 2005.

[34] R. M. Eglen, "Emerging concepts in GPCR functionthe influence of cell phenotype on GPCR pharmacology," Proceedings of the Western Pharmacology Society, vol. 48, pp. 31-34, 2005.

[35] R. M. Eglen, R. Bosse, and T. Reisine, "Emerging concepts of guanine nucleotide-binding protein-coupled receptor (GPCR) function and implications for high throughput screening," Assay and Drug Development Technologies, vol. 5, no. 3, pp. 425-451, 2007.

[36] A. Ignatov, J. Lintzel, I. Hermans-Borgmeyer et al., "Role of the G-protein-coupled receptor GPR12 as high-affinity receptor for sphingosylphosphorylcholine and its expression and function in brain development," Journal of Neuroscience, vol. 23, no. 3, pp. 907-914, 2003.

[37] A. Zaslavsky, L. S. Singh, H. Tan, H. Ding, Z. Liang, and Y. $\mathrm{Xu}$, "Homo- and hetero-dimerization of LPA/S1P receptors, OGR1 and GPR4," Biochimica et Biophysica Acta, vol. 1761, no. 10, pp. 1200-1212, 2006.

[38] H. Rosen, P. J. Gonzalez-Cabrera, M. G. Sanna, and S. Brown, "Sphingosine 1-phosphate receptor signaling," Annual Review of Biochemistry, vol. 78, pp. 743-768, 2009.

[39] E. Afrasiabi, T. Blom, E. Ekokoski, R. K. Tuominen, and K. Törnquist, "Sphingosylphosphorylcholine enhances calcium entry in thyroid FRO cells by a mechanism dependent on protein kinase C," Cellular Signalling, vol. 18, no. 10, pp. 1671-1678, 2006.

[40] A. Kleger, T. Busch, S. Liebau et al., "The bioactive lipid sphingosylphosphorylcholine induces differentiation of mouse embryonic stem cells and human promyelocytic leukaemia cells," Cellular Signalling, vol. 19, no. 2, pp. 367-377, 2007.

[41] A. Rodgers, D. Mormeneo, J. S. Long, A. Delgado, N. J. Pyne, and S. Pyne, "Sphingosine 1-phosphate regulation of extracellular signal-regulated kinase-1/2 in embryonic stem cells," Stem Cells and Development, vol. 18, no. 9, pp. 13191330, 2009.

[42] K. S. Kim, J. Ren, Y. Jiang et al., "GPR4 plays a critical role in endothelial cell function and mediates the effects of sphingosylphosphorylcholine," FASEB Journal, vol. 19, no. 7, pp. 819-821, 2005.
[43] M. R. Steiner, J. R. Urso, J. Klein, and S. M. Steiner, "Multiple astrocyte responses to lysophosphatidic acids," Biochimica et Biophysica Acta, vol. 1582, no. 1-3, pp. 154-160, 2002.

[44] A. E. Alewijnse, S. L. M. Peters, and M. C. Michel, "Cardiovascular effects of sphingosine-1-phosphate and other sphingomyelin metabolites," British Journal of Pharmacology, vol. 143, no. 6, pp. 666-684, 2004.

[45] J. R. Nofer, M. Van Der Giet, M. Tölle et al., "HDL induces NO-dependent vasorelaxation via the lysophospholipid receptor S1P3," Journal of Clinical Investigation, vol. 113, no. 4, pp. 569-581, 2004.

[46] P. D. Lambiase, R. J. Edwards, P. Anthopoulos et al., "Circulating humoral factors and endothelial progenitor cells in patients with differing coronary collateral support," Circulation, vol. 109, no. 24, pp. 2986-2992, 2004.

[47] J. M. Isner, C. Kalka, A. Kawamoto, and T. Asahara, "Bone marrow as a source of endothelial cells for natural and iatrogenic vascular repair," Annals of the New York Academy of Sciences, vol. 953, pp. 75-84, 2001.

[48] U. Landmesser, N. Engberding, F. H. Bahlmann et al., "Statin-induced improvement of endothelial progenitor cell mobilization, myocardial neovascularization, left ventricular function, and survival after experimental myocardial infarction requires endothelial nitric oxide synthase," Circulation, vol. 110, no. 14, pp. 1933-1939, 2004.

[49] L. V. Yang, C. G. Radu, M. Roy et al., "Vascular abnormalities in mice deficient for the G protein-coupled receptor GPR4 that functions as a $\mathrm{pH}$ sensor," Molecular and Cellular Biology, vol. 27, no. 4, pp. 1334-1347, 2007.

[50] E. S. Jeon, H. J. Moon, M. J. Lee et al., "Sphigosylphosphorylcholine induces differentiation of human mesenchymal stem cells into smooth-muscle-like through a TGF- $\beta$-dependent mechanism," Journal of Cell Science, vol. 119, no. 23, pp. 4994-5005, 2006.

[51] E. S. Jeon, H. Y. Song, M. R. Kim et al., "Sphingosylphosphorylcholine induces proliferation of human adipose tissuederived mesenchymal stem cells via activation of JNK," Journal of Lipid Research, vol. 47, no. 3, pp. 653-664, 2006.

[52] S. J. Kattman, T. L. Huber, and G. Keller, "Multipotent Flk-1+ cardiovascular progenitor cells give rise to the cardiomyocyte, endothelial, and vascular smooth muscle lineages," Developmental Cell, vol. 11, no. 5, pp. 723-732, 2006.

[53] T. Seufferlein and E. Rozengurt, "Sphingosylphosphorylcholine rapidly induces tyrosine phosphorylation of p125(FAK) and paxillin, rearrangement of the actin cytoskeleton and focal contact assembly. Requirement of p21(rho) in the signaling pathway," Journal of Biological Chemistry, vol. 270, no. 41, pp. 24343-24351, 1995.

[54] T. Seufferlein and E. Rozengurt, "Sphingosylphosphorylcholine activation of mitogen-activated protein kinase in Swiss 3T3 cells requires protein kinase $\mathrm{C}$ and a pertussis toxin-sensitive G protein," Journal of Biological Chemistry, vol. 270, no. 41, pp. 24334-24342, 1995.

[55] A. Sachinidis, C. Gissel, D. Nierhoff et al., "Identification of plateled-derived growth factor-BB as cardiogenesis- inducing factor in mouse embryonic stem cells under serum-free conditions," Cellular Physiology and Biochemistry, vol. 13, no. 6, pp. 423-429, 2003.

[56] G. Boguslawski, J. R. Grogg, Z. Welch et al., "Migration of vascular smooth muscle cells induced by sphingosine 1phosphate and related lipids: potential role in the angiogenic response," Experimental Cell Research, vol. 274, no. 2, pp. 264-274, 2002. 
[57] G. Boguslawski, D. Lyons, K. A. Harvey, A. T. Kovala, and D. English, "Sphingosylphosphorylcholine induces endothelial cell migration and morphogenesis," Biochemical and Biophysical Research Communications, vol. 272, no. 2, pp. 603-609, 2000.

[58] F. A. Mathieson and G. F. Nixon, "Sphingolipids differentially regulate mitogen-activated protein kinases and intracellular $\mathrm{Ca}^{2+}$ in vascular smooth muscle: effects on CREB activation," British Journal of Pharmacology, vol. 147, no. 4, pp. 351-359, 2006.

[59] D. G. Hemmings, "Signal transduction underlying the vascular effects of sphingosine 1-phosphate and sphingosylphosphorylcholine," Naunyn-Schmiedeberg's Archives of Pharmacology, vol. 373, no. 1, pp. 18-29, 2006.

[60] Y. J. Piao, C. H. Lee, M. J. Zhu et al., "Involvement of urokinase-type plasminogen activator in sphingosylphosphorylcholine-induced angiogenesis," Experimental Dermatology, vol. 14, no. 5, pp. 356-362, 2005.

[61] E. S. Jeon, Y. J. Kang, H. Y. Song et al., "Role of MEK-ERK pathway in sphingosylphosphorylcholine-induced cell death in human adipose tissue-derived mesenchymal stem cells," Biochimica et Biophysica Acta, vol. 1734, no. 1, pp. 25-33, 2005.

[62] H. J. Moon, E. S. Jeon, Y. M. Kim, M. J. Lee, C. K. Oh, and J. H. Kim, "Sphingosylphosphorylcholine stimulates expression of fibronectin through TGF- $\beta 1$-smad-dependent mechanism in human mesenchymal stem cells," International Journal of Biochemistry and Cell Biology, vol. 39, no. 6, pp. 1224-1234, 2007.

[63] G. D. Norata, E. Callegari, M. Marchesi, G. Chiesa, P. Eriksson, and A. L. Catapano, "High-density lipoproteins induce transforming growth factor- $\beta 2$ expression in endothelial cells," Circulation, vol. 111, no. 21, pp. 2805-2811, 2005.

[64] I. Ishii, B. Friedman, X. Ye et al., "Selective loss of sphingosine 1-phosphate signaling with No obvious phenotypic abnormality in mice lacking its $\mathrm{G}$ protein-coupled receptor, LP B3/EDG-3," Journal of Biological Chemistry, vol. 276, no. 36, pp. 33697-33704, 2001.

[65] Q. Zhang, O. Peyruchaud, K. J. French, M. K. Magnusson, and D. F. Mosher, "Sphingosine 1-phosphate stimulates fibronectin matrix assembly through a Rho-dependent signal pathway," Blood, vol. 93, no. 9, pp. 2984-2990, 1999.

[66] H. M. Himmel, D. Meyer Zu Heringdorf, E. Graf et al., "Evidence for Edg-3 receptor-mediated activation of I(K.ACh) by sphingosine-1-phosphate in human atrial cardiomyocytes," Molecular Pharmacology, vol. 58, no. 2, pp. 449-454, 2000.

[67] D. Mazurais, P. Robert, B. Gout, I. Berrebi-Bertrand, M. P. Laville, and T. Calmels, "Cell type-specific localization of human cardiac S1P receptors," Journal of Histochemistry and Cytochemistry, vol. 50, no. 5, pp. 661-670, 2002.

[68] T. Kimura, T. Watanabe, K. Sato et al., "Sphingosine 1phosphate stimulates proliferation and migration of human endothelial cells possibly through the lipid receptors, Edg-1 and Edg-3," Biochemical Journal, vol. 348, part 1, pp. 71-76, 2000.

[69] F. Wang, J. R. Van Brooklyn, J. P. Hobson et al., "Sphingosine 1-phosphate stimulates cell migration through a G(i)-coupled cell surface receptor. Potential involvement in angiogenesis," Journal of Biological Chemistry, vol. 274, no. 50, pp. 35343-35350, 1999.

[70] C. K. Means, C. Y. Xiao, Z. Li et al., "Sphingosine 1phosphate S1P2 and S1P3 receptor-mediated Akt activation protects against in vivo myocardial ischemia-reperfusion injury," American Journal of Physiology-Heart and Circulatory Physiology, vol. 292, no. 6, pp. H2944-H2951, 2007.

[71] G. Theilmeier, C. Schmidt, J. Herrmann et al., "High-density lipoproteins and their constituent, sphingosine-1-phosphate, directly protect the heart against ischemia/reperfusion injury in vivo via the S1P3 lysophospholipid receptor," Circulation, vol. 114, no. 13, pp. 1403-1409, 2006.

[72] J. Zhang, N. Honbo, E. J. Goetzl, K. Chatterjee, J. S. Karliner, and M. O. Gray, "Signals from type 1 sphingosine 1phosphate receptors enhance adult mouse cardiac myocyte survival during hypoxia," American Journal of PhysiologyHeart and Circulatory Physiology, vol. 293, no. 5, pp. H3150H3158, 2007.

[73] P. Robert, P. Tsui, M. P. Laville et al., "EDG1 receptor stimulation leads to cardiac hypertrophy in rat neonatal myocytes," Journal of Molecular and Cellular Cardiology, vol. 33, no. 9, pp. 1589-1606, 2001.

[74] P. Bandhuvula, N. Honbo, G. Y. Wang et al., "S1P lyase (SPL): a novel therapeutic target for ischemia/reperfusion injury of the heart," American Journal of Physiology-Heart and Circulatory Physiology, vol. 300, no. 5, pp. H1753-H1761, 2011.

[75] D. A. Vessey, M. Kelley, L. Li, and Y. Huang, "Sphingosine protects aging hearts from ischemia/reperfusion injury: superiority to sphingosine 1-phosphate and ischemic preand post-conditioning," Oxidative Medicine and Cellular Longevity, vol. 2, no. 3, pp. 146-151, 2009.

[76] E. Kupperman, S. An, N. Osborne, S. Waldron, and D. Y. R. Stainier, "A sphingosine-1-phosphate receptor regulates cell migration during vertebrate heart development," Nature, vol. 406, no. 6792, pp. 192-195, 2000.

[77] A. Kawahara, T. Nishi, Y. Hisano, H. Fukui, A. Yamaguchi, and N. Mochizuki, "The sphingolipid transporter Spns2 functions in migration of zebrafish myocardial precursors," Science, vol. 323, no. 5913, pp. 524-527, 2009.

[78] T. Matsui, A. Raya, C. Callol-Massot et al., "Miles-apartMediated regulation of cell-fibronectin interaction and myocardial migration in zebrafish," Nature Clinical Practice Cardiovascular Medicine, vol. 4, supplement 1, pp. S77-S82, 2007.

[79] C. C. Wendler and S. A. Rivkees, "Sphingosine-1-phosphate inhibits cell migration and endothelial to mesenchymal cell transformation during cardiac development," Developmental Biology, vol. 291, no. 2, pp. 264-277, 2006.

[80] N. Osborne, K. Brand-Arzamendi, E. A. Ober et al., "The spinster homolog, two of hearts, is required for sphingosine 1-phosphate signaling in zebrafish," Current Biology, vol. 18, no. 23, pp. 1882-1888, 2008.

[81] J. L. Edwards, W. A. King, S. J. Kawarsky, and A. D. Ealy, "Responsiveness of early embryos to environmental insults: potential protective roles of HSP70 and glutathione," Theriogenology, vol. 55, no. 1, pp. 209-223, 2001.

[82] J. S. Karliner, N. Honbo, K. Summers, M. O. Gray, and E. J. Goetzl, "The lysophospholipids sphingosine-1-phosphate and lysophosphatidic acid enhance survival during hypoxia in neonatal rat cardiac myocytes," Journal of Molecular and Cellular Cardiology, vol. 33, no. 9, pp. 1713-1717, 2001.

[83] S. Pyne and N. J. Pyne, "Sphingosine 1-phosphate signalling in mammalian cells," Biochemical Journal, vol. 349, no. 2, pp. 385-402, 2000.

[84] K. Inniss and H. Moore, "Mediation of apoptosis and proliferation of human embryonic stem cells by sphingosine1-phosphate," Stem Cells and Development, vol. 15, no. 6, pp. 789-796, 2006. 
[85] X. Shu, W. Wu, R. D. Mosteller, and D. Broek, "Sphingosine kinase mediates vascular endothelial growth factor-induced activation of ras and mitogen-activated protein kinases," Molecular and Cellular Biology, vol. 22, no. 22, pp. 7758-7768, 2002.

[86] C. P. Chang, J. R. Neilson, J. H. Bayle et al., "A field of myocardial-endocardial NFAT signaling underlies heart valve morphogenesis," Cell, vol. 118, no. 5, pp. 649-663, 2004.

[87] J. Igarashi, P. A. Erwin, A. P. V. Dantas, H. Chen, and T. Michel, "VEGF induces S1P1 receptors in endothelial cells: implications for cross-talk between sphingolipid and growth factor receptors," Proceedings of the National Academy of Sciences of the United States of America, vol. 100, no. 19, pp. 10664-10669, 2003.

[88] A. Endo, K. I. Nagashima, H. Kurose, S. Mochizuki, M. Matsuda, and N. Mochizuki, "Sphingosine 1-phosphate induces membrane ruffling and increases motility of human umbilical vein endothelial cells via vascular endothelial growth factor receptor and CrkII," Journal of Biological Chemistry, vol. 277, no. 26, pp. 23747-23754, 2002.

[89] C. B. Fieber, J. Eldridge, T. A. Taha, L. M. Obeid, and R. C. Muise-Helmericks, "Modulation of total Akt kinase by increased expression of a single isoform: requirement of the sphingosine-1-phosphate receptor, Edg3/S1P3, for the VEGF-dependent expression of Akt3 in primary endothelial cells," Experimental Cell Research, vol. 312, no. 7, pp. 11641173, 2006.

[90] S. S. Chae, J. H. Paik, M. L. Allende, R. L. Proia, and T. Hla, "Regulation of limb development by the sphingosine 1-phosphate receptor S1p1/EDG-1 occurs via the hypoxia/VEGF axis," Developmental Biology, vol. 268, no. 2, pp. 441-447, 2004.

[91] M. J. Lee, S. Thangada, K. P. Claffey et al., "Vascular endothelial cell adherens junction assembly and morphogenesis induced by sphingosine-1-phosphate," Cell, vol. 99, no. 3, pp. 301-312, 1999.

[92] K. J. Bayless and G. E. Davis, "Sphingosine-1-phosphate markedly induces matrix metalloproteinase and integrindependent human endothelial cell invasion and lumen formation in three-dimensional collagen and fibrin matrices," Biochemical and Biophysical Research Communications, vol. 312, no. 4, pp. 903-913, 2003.

[93] S. I. Miura, H. Tanigawa, Y. Matsuo, M. Fujino, A. Kawamura, and K. Saku, "Ras/Raf1-dependent signal in sphingosine-1-phosphate-induced tube formation in human coronary artery endothelial cells," Biochemical and Biophysical Research Communications, vol. 306, no. 4, pp. 924-929, 2003.

[94] Y. Matsuo, S. I. Miura, A. Kawamura, Y. Uehara, K. A. Rye, and K. Saku, "Newly developed reconstituted high-density lipoprotein containing sphingosine-1-phosphate induces endothelial tube formation," Atherosclerosis, vol. 194, no. 1, pp. 159-168, 2007.

[95] W. Risau and I. Flamme, "Vasculogenesis," Annual Review of Cell and Developmental Biology, vol. 11, pp. 73-91, 1995.

[96] K. A. Harvey, Z. Welch, D. Sliva, and R. A. Siddiqui, "Role of Rho kinase in sphingosine 1-phosphate-mediated endothelial and smooth muscle cell migration and differentiation," Molecular and Cellular Biochemistry, vol. 342, no. 1-2, pp. 719, 2010.

[97] K. Lockman, J. S. Hinson, M. D. Medlin, D. Morris, J. M. Taylor, and C. P. Mack, "Sphingosine 1-phosphate stimulates smooth muscle cell differentiation and proliferation by activating separate serum response factor co-factors," Journal of Biological Chemistry, vol. 279, no. 41, pp. 42422-42430, 2004.

[98] Y. Liu, R. Wada, T. Yamashita et al., "Edg-1, the G proteincoupled receptor for sphingosine-1-phosphate, is essential for vascular maturation," Journal of Clinical Investigation, vol. 106, no. 8, pp. 951-961, 2000.

[99] M. L. Allende, T. Yamashita, and R. L. Proia, "G-proteincoupled receptor S1P1 acts within endothelial cells to regulate vascular maturation," Blood, vol. 102, no. 10, pp. 3665-3667, 2003.

[100] B. Annabi, S. Thibeault, Y. T. Lee et al., "Matrix metalloproteinase regulation of sphingosine-1-phosphate-induced angiogenic properties of bone marrow stromal cells," Experimental Hematology, vol. 31, no. 7, pp. 640-649, 2003.

[101] A. J. MacLennan, P. R. Carney, W. J. Zhu et al., "An essential role for the H218/AGR16/Edg-5/LPB2 sphingosine 1-phosphate receptor in neuronal excitability," European Journal of Neuroscience, vol. 14, no. 2, pp. 203-209, 2001.

[102] M. Kono, Y. Mi, Y. Liu et al., "The sphingosine-1-phosphate receptors S1P1, S1P2, and S1P3 function coordinately during embryonic angiogenesis," Journal of Biological Chemistry, vol. 279, no. 28, pp. 29367-29373, 2004.

[103] J. N. Lorenz, L. J. Arend, R. Robitz, R. J. Paul, and A. J. MacLennan, "Vascular dysfunction in S1P2 sphingosine 1-phosphate receptor knockout mice," American Journal of Physiology-Regulatory, Integrative and Comparative Physiology, vol. 292, pp. R440-R446, 2007.

[104] M. Kono, I. A. Belyantseva, A. Skoura et al., "Deafness and stria vascularis defects in S1P2 receptor-null mice," Journal of Biological Chemistry, vol. 282, no. 14, pp. 10690-10696, 2007.

[105] A. Skoura, T. Sanchez, and K. Claffey, "Essential role of sphingosine 1-phosphate receptor 2 in pathological angiogenesis of the mouse retina," The Journal of Clinical Investigation, vol. 117, no. 9, pp. 2506-2516, 2007.

[106] M. Sata, "Role of circulating vascular progenitors in angiogenesis, vascular healing, and pulmonary hypertension: lessons from animal models," Arteriosclerosis, Thrombosis, and Vascular Biology, vol. 26, pp. 1008-1014, 2006.

[107] M. Hristov and C. Weber, "Endothelial progenitor cells: characterization, pathophysiology, and possible clinical relevance," Journal of Cellular and Molecular Medicine, vol. 8, no. 4, pp. 498-508, 2004.

[108] G. Seitz, A. M. Boehmler, L. Kanz, and R. Möhle, "The role of sphingosine 1-phosphate receptors in the trafficking of hematopoietic progenitor cells," Annals of the New York Academy of Sciences, vol. 1044, pp. 84-89, 2005.

[109] D. H. Walter, U. Rochwalsky, J. Reinhold et al., "Sphingosine1-phosphate stimulates the functional capacity of progenitor cells by activation of the CXCR4-dependent signaling pathway via the S1P3 receptor," Arteriosclerosis, Thrombosis, and Vascular Biology, vol. 27, pp. 275-282, 2007.

[110] C. Donati, F. Cencetti, P. Nincheri et al., "Sphingosine 1phosphate mediates proliferation and survival of mesoangioblasts," Stem Cells, vol. 25, no. 7, pp. 1713-1719, 2007.

[111] X. Chen, X. Y. Yang, N. D. Wang et al., "Serum lysophosphatidic acid concentrations measured by dot immunogold filtration assay in patients with acute myocardial infarction," Scandinavian Journal of Clinical \& Laboratory Investigation, vol. 63, pp. 497-503, 2003.

[112] J. Chen, Y. Chen, W. Zhu et al., "Specific LPA receptor subtype mediation of LPA-induced hypertrophy of cardiac myocytes and involvement of Akt and NFkappaB signal pathways," Journal of Cellular Biochemistry, vol. 103, no. 6, pp. 1718-1731, 2008. 
[113] R. Hilal-Dandan, C. K. Means, A. B. Gustafsson et al., "Lysophosphatidic acid induces hypertrophy of neonatal cardiac myocytes via activation of Gi and Rho," Journal of Molecular and Cellular Cardiology, vol. 36, no. 4, pp. 481-493, 2004.

[114] T. S. Panetti, D. F. Hannah, C. Avraamides et al., "Extracellular matrix molecules regulate endothelial cell migration stimulated by lysophosphatidic acid," Journal of Thrombosis and Haemostasis, vol. 2, pp. 1645-1656, 2004.

[115] W. T. Wu, C. N. Chen, C. I. Lin, J. H. Chen, and H. Lee, "Lysophospholipids enhance matrix metalloproteinase2 expression in human endothelial cells," Endocrinology, vol. 146, no. 8, pp. 3387-3400, 2005.

[116] M. J. Lee, S. Thangada, C. H. Liu, B. D. Thompson, and T. Hla, "Lysophosphatidic acid stimulates the G-proteincoupled receptor EDG-1 as a low affinity agonist," Journal of Biological Chemistry, vol. 273, no. 34, pp. 22105-22112, 1998.

[117] S. Langlois, D. Gingras, and R. Béliveau, "Membrane type 1-matrix metalloproteinase (MT1-MMP) cooperates with sphingosine 1-phosphate to induce endothelial cell migration and morphogenic differentiation," Blood, vol. 103, no. 8, pp. 3020-3028, 2004.

[118] K. M. Argraves, B. A. Wilkerson, W. S. Argraves, P. A. Fleming, L. M. Obeid, and C. J. Drake, "Sphingosine-1phosphate signaling promotes critical migratory events in vasculogenesis," Journal of Biological Chemistry, vol. 279, no. 48, pp. 50580-50590, 2004.

[119] J. J. A. Contos, N. Fukushima, J. A. Weiner, D. Kaushal, and J. Chun, "Requirement for the $1 \mathrm{p}(\mathrm{A} 1)$ lysophosphatidic acid receptor gene in normal suckling behavior," Proceedings of the National Academy of Sciences of the United States of America, vol. 97, no. 24, pp. 13384-13389, 2000.

[120] J. J. A. Contos, I. Ishii, N. Fukushima et al., "Characterization of lpa2 (Edg4) and lpa1/lpa2 (Edg2/Edg4) lysophosphatidic acid receptor knockout mice: signaling deficits without obvious phenotypic abnormality attributable to lpa2," Molecular and Cellular Biology, vol. 22, no. 19, pp. 6921-6929, 2002.

[121] H. Sumida, K. Noguchi, Y. Kihara et al., "LPA4 regulates blood and lymphatic vessel formation during mouse embryogenesis," Blood, vol. 116, no. 23, pp. 5060-5070, 2010.

[122] L. A. Van Meeteren, P. Ruurs, C. Stortelers et al., "Autotaxin, a secreted lysophospholipase D, is essential for blood vessel formation during development," Molecular and Cellular Biology, vol. 26, no. 13, pp. 5015-5022, 2006.

[123] S. Offermanns, V. Mancino, J. P. Revel, and M. I. Simon, "Vascular system defects and impaired cell chemokinesis as a result of G $\alpha 13$ deficiency," Science, vol. 275, no. 5299, pp. 533-536, 1997.

[124] D. Escalante-Alcalde, L. Hernandez, H. Le Stunff et al., "The lipid phosphatase LPP3 regulates extra-embryonic vasculogenesis and axis patterning," Development, vol. 130, no. 19, pp. 4623-4637, 2003. 

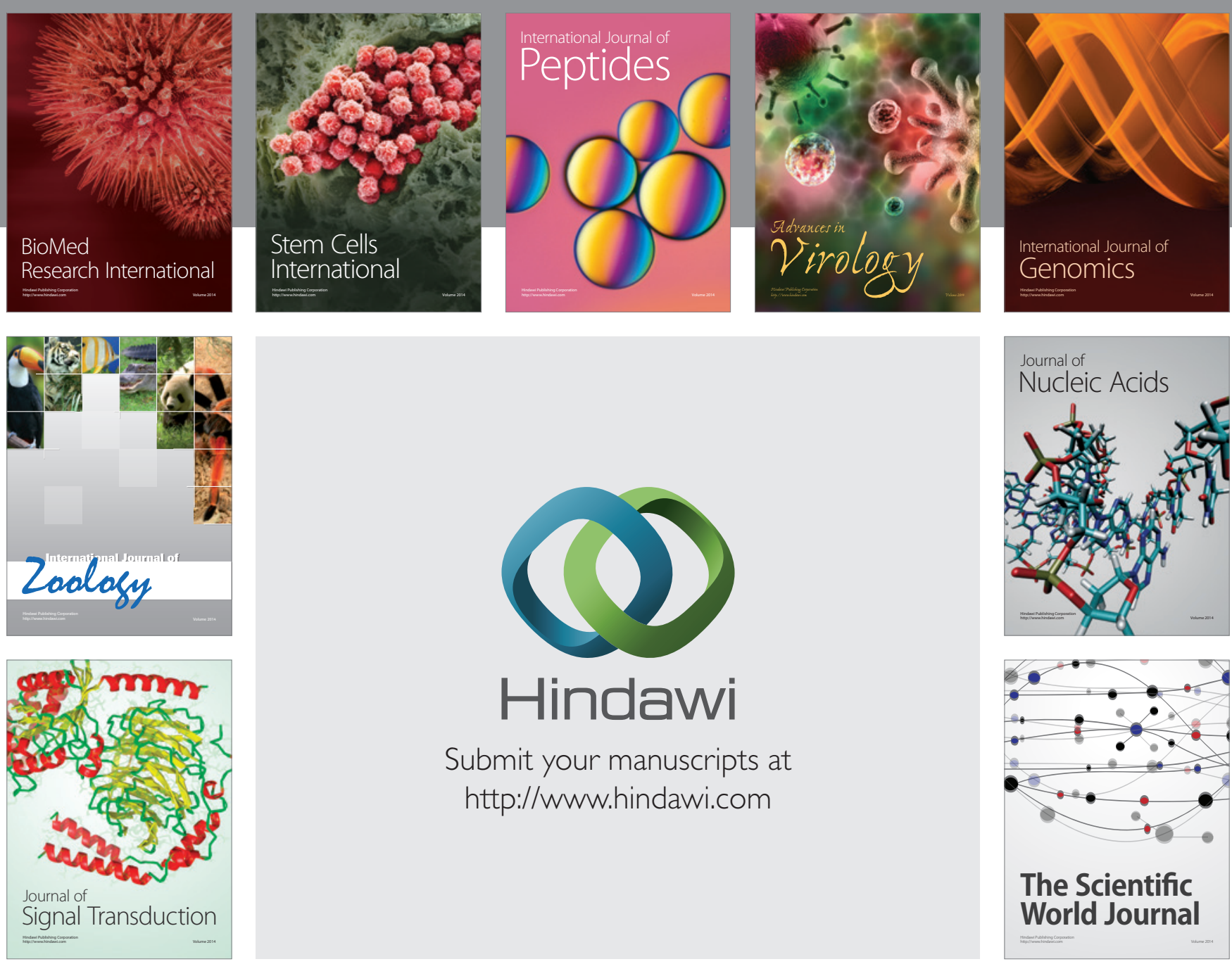

Submit your manuscripts at

http://www.hindawi.com
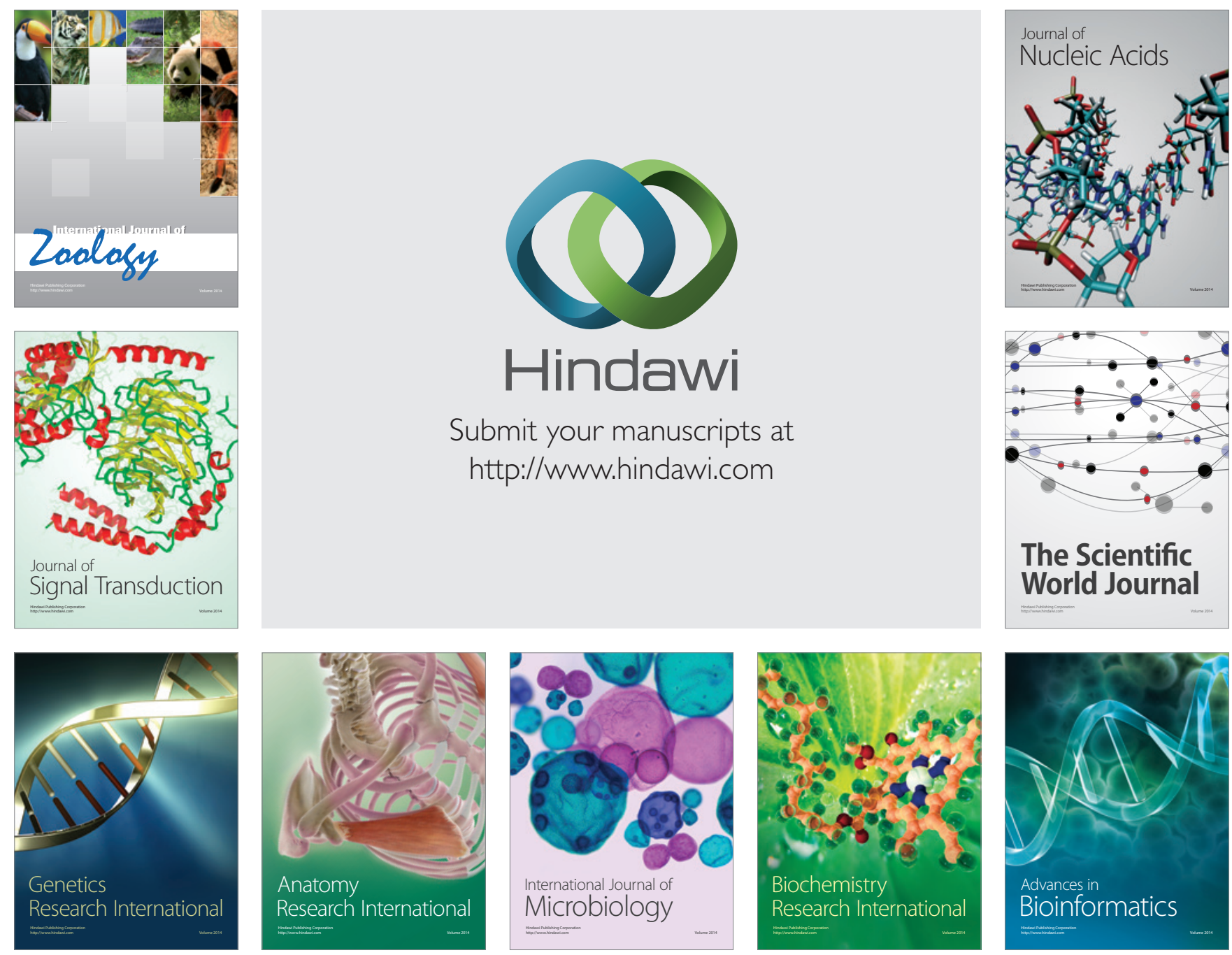

The Scientific World Journal
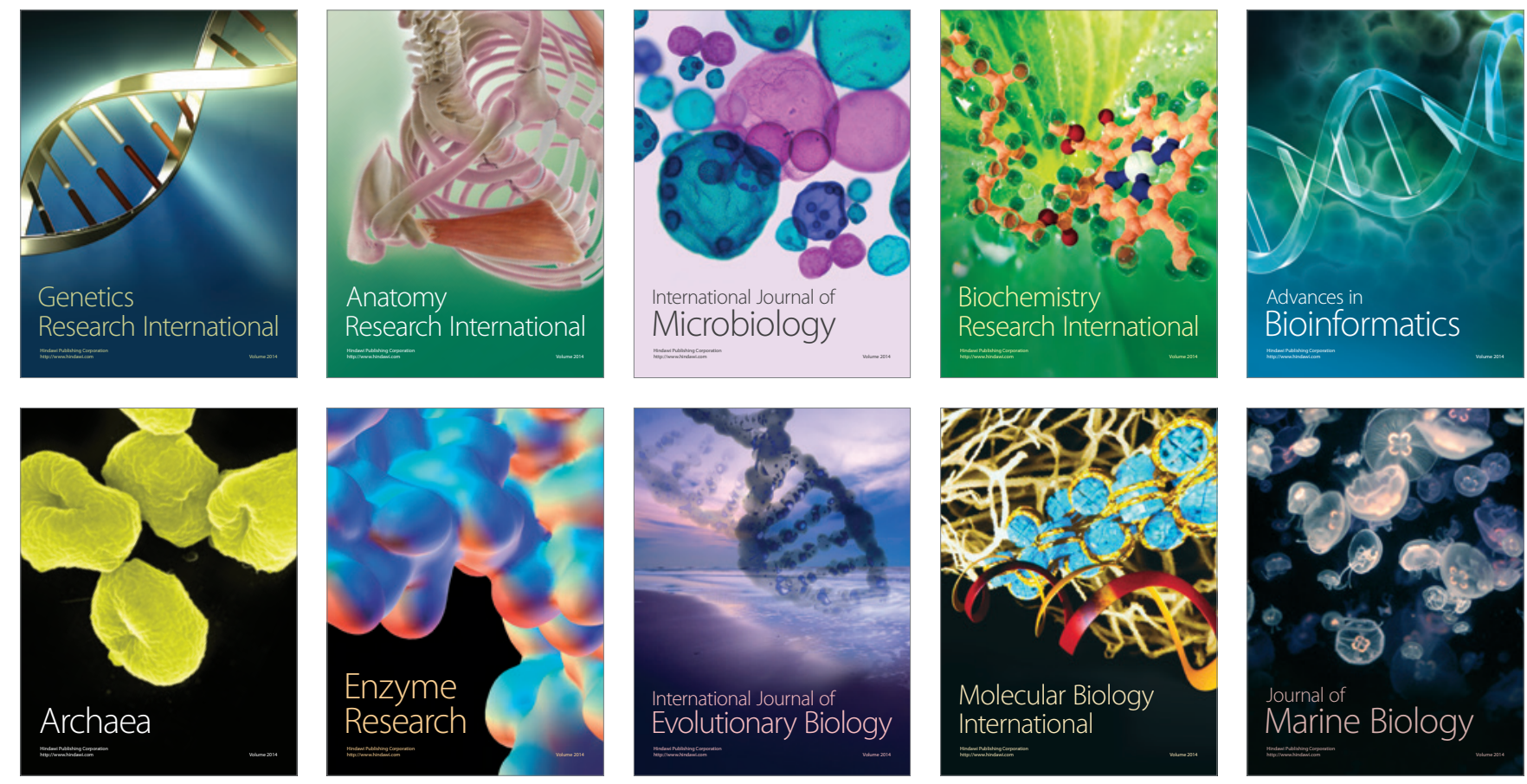